\title{
Sensor Kebocoran Arus Listrik Water Heater Elektrik
}

\author{
Hartono $^{(1)^{*}}$, Sugito ${ }^{(1)}$ dan R.Farzand Abdullatif ${ }^{(1)}$ \\ (1) Jurusan Fisika Fakultas MIPA \\ Jln. Dr.Soeparno 61 Karangwangkal Purwokerto \\ *Email: harlaras@gmail.com
}

Diterima (15 Mei 2018), diervisi (31 Mei 2018)

\begin{abstract}
An electric current sensor detecting current leak into water flowing out from a water heater has been constructed. The sensor is made of a copper electrode implanted in a PVC pipe. It is subjected to tests in which the voltage is varied at constant resistance and otherwise the resistance is varied at constant voltage. The variation of the AC voltage is conducted from 0 to 220 volt whereas that of the resistance is from $1 \mathrm{~K} \Omega$ to $100 \mathrm{~K} \Omega$. The $1 \mathrm{~K} \Omega$ resistance is meant to represent the resistance of human skin in wet condition and the $100 \mathrm{~K} \Omega$ represents that of dry insulated skin. Analysis shows that unpainful shock sensation surges at $30 \mathrm{~V}, 5.16 \mathrm{~mA}$, with $1 \mathrm{~K} \Omega$ resistance. In the current leak condition at $220 \mathrm{~V}$, unpainful shock is sensed at body resistance of $42 \mathrm{~K} \Omega$ with $4,99 \mathrm{~mA}$ current.
\end{abstract}

Keywords: Current sensor, current leak, water heater, unpainful shock

\begin{abstract}
Abstrak. Sensor arus listrik merupakan sensor yang dapat mendeteksi terjadinya kebocoran arus listrik pada water heater. Sensor akan mendeteksi terjadinya kebocoran arus listrik dalam aliran air dari water heater. Sensor dibuat dari elektroda tembaga yang ditanam dalam pipa PVC. Pengujian sensor dilakukan terhadap variasi tegangan pada hambatan tetap dan variasi hambatan pada tegangan tetap. Variasi tegangan AC dilakukan dari 0 sampai 220 volt sementara variasi hambatan mulai dari $1 \mathrm{~K} \Omega$ sampai $100 \mathrm{~K} \Omega$. Kondisi hambatan $1 \mathrm{~K} \Omega$ mewakili hambatan kulit tubuh manusia dalam keadaan basah dan $100 \mathrm{~K} \Omega$ mewakili hambatan kulit tubuh dalam keadaan kering terisolasi. Hasil analisis menunjukkan bahwa sensasi syok tidak nyeri mulai dapat dirasakan pada tegangan $30 \mathrm{~V}$ arus sebesar $5,16 \mathrm{~mA}$ pada kondisi hambatan $1 \mathrm{~K} \Omega$. Sementara pada kondisi kebocoran tegangan $220 \mathrm{~V}$, sensasi syok tidak nyeri mulai dirasakan pada kondisi hambatan tubuh $42 \mathrm{~K} \Omega$ dengan arus sebesar 4,99 mA.
\end{abstract}

Kata kunci: sensor arus, kebocoran arus listrik, water heater, syok tidak nyeri.

\section{PENDAHULUAN}

Kebocoran arus listrik pada water heater merupakan masalah yang serius. Arus listrik tidak hanya mengalir melalui bahan penghantar atau konduktor padat, melainkan juga dapat terjadi melalui medium cair, seperti air. Akibat terjadinya kebocoran arus listrik dapat menyebabkan terjadinya sengatan listrik pada tubuh manusia. Kebocoran arus listrik dari pemanas air elektrik pernah terjadi dan tidak terdeteksi secara visual, akibatnya adalah pengguna meninggal dunia.

Setiap penghantar mempunyai hambatan yang bervariasi dalam mengalirkan arus listrik. Tubuh manusia merupakan salah satu penghantar listrik yang baik sekalipun tubuh manusia memiliki hambatan listrik. Hambatan tubuh manusia pada kondisi kulit kering berkisar antara 1000 sampai dengan $100.000 \Omega$, 
sedangkan pada kondisi kulit basah akan menurun sampai $\leq 1000 \Omega$ [1]. Sengatan arus listrik yang terjadi pada tubuh manusia akan memberikan dampak negatif yang bervariasi. Dampak yang dapat terjadi mulai yang paling ringan adalah kejutan otot, kejang pada sebagian organ termasuk jantung sampai pada terbakarnya jaringan tubuh[2]. Kejadian sengatan arus listrik yang selama ini sering terjadi adalah karena aliran arus listrik bolak balik (AC).Berdasarkan pada penelitian yang pernah dilakukan Cekin N, dkk menunjukkan bahwa kematian akibat sengatan listrik tegangan rendah di rumah tangga dan tempat kerja mencapai $34,9 \%$ [3].

Perubahan polaritas yang terjadi setiap waktu menyatakan frekuensi dari arus AC. Frekuensi arus AC akan mempengaruhi kontraksi pada otot. Hal ini yang menyebabkan arus AC jauh lebih berbahaya dibandingkan arus DC pada nilai tegangan yang sama[4]. Sengatan arus listrik AC dapat mengakibatkan kontraksi otot secara terus menerus selama aliran arus belum terputus. Hal ini menyebabkan korban mengalami kejang pada bagian organ-organ tubuhnya termasuk tangan dan kaki. Hal ini yang menyebabkan korban tidak mempunyai kemampuan untuk melepaskan diri dari sengatan arus listrik. Otot rangka merupakan jaringan yang membawa arus listrik paling besar karena otot rangka memiliki proporsi volum yang paling besar dibandingkan jaringan lainnya [5].
Pengaruh yang dapat terjadi akibat sengatan listrik adalah kerusakan organ atau jaringan tubuh. Tingkat kerusakan yang terjadi pada tubuh korban dipengaruhi oleh hambatan tubuh, tegangan dan arus listriknya. Hambatan tubuh dipengaruhi oleh tingkat kebasahan bagian luar tubuh. Hambatan tubuh yang basah atau berkeringat akan menurun sampai $\leq 1000$ $\Omega$. Penurunan hambatan tubuh akan memudahkan arus listrik masuk dalam tubuh. Semakin besar arus listrik yang masuk dalam tubuh akan semakin besar juga pengaruh yang terjadi. Pengaruh sengatan listrik pada tubuh manusia pada berbagai nilai arus seperti terlihat pada Tabel 1.

Sesuai dengan hukum Kirchhoff, aliran arus listrik (I) hanya akan terjadi dalam loop tertutup. Dalam sebuah loop tertutup terdiri dari sumber tegangan dan hambatan yang terhubung sehingga menyebabkan terjadinya aliran arus listrik. Tubuh manusia merupakan salah satu penghantar sekaligus hambatan untuk membentuk loop tertutup.Menurut hukum Ohm, kemudahan aliran muatan listrik pada suatu penghantar ditentukan oleh dua faktor, yaitu hambatan (R) dari penghantar dan beda potensial (V) pada kedua ujungnya[6], sehingga dapat dituliskan sebagai berikut:

$I=\frac{V}{R}$

Tabel 1. Pengaruh sengatan listrik terhadap organ tubuh manusia dengan asumsi terjadi kontak langsung dengan kulit (Prasad, Sharma, \& Sharma, 2010).

\begin{tabular}{llll}
\hline \multirow{2}{*}{$(\mathbf{m A})$} & \multirow{2}{*}{ Efek fisiologis } & \multicolumn{2}{c}{$\mathbf{V}($ Volt) pada $\mathbf{R}$ tubuh } \\
\cline { 3 - 4 } & & $\mathbf{1 0 0 0} \boldsymbol{\Omega}$ & $\mathbf{1 0 0 0 0 0} \boldsymbol{\Omega}$ \\
\hline 1 & batas ambang merasa geli & 1 & 10 \\
\hline 5 & sensasi syok, tidak nyeri & 5 & 500 \\
\hline $10-20$ & $\begin{array}{l}\text { nyeri disertai kontraksi otot yang hebat dan kesulitan } \\
\text { bernafas }\end{array}$ & 10 & 1000 \\
\hline $100-300$ & fibrilasi ventrikel dan kelumpuhan pernafasan & 100 & 10000 \\
\hline 6000 & fibrilasi ventrikel, kelumpuhan pernafasan, dan luka bakar & 6000 & 600000 \\
\hline
\end{tabular}




\section{METODE PENELITIAN}

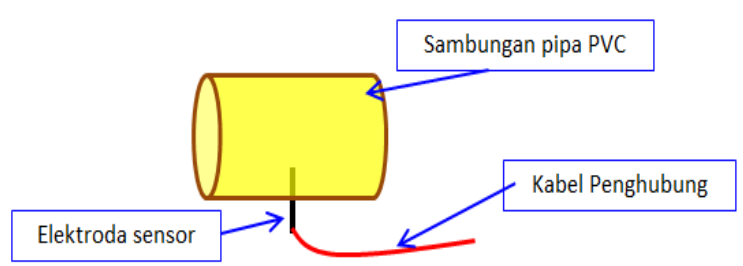

Gambar 1. Rancangan sensor kebocoran arus listrik

Penelitian dilakukan dengan metode eksperimen di laboratorium. Sensor digunakan untuk mendeteksi terjadinya kebocoran arus listrik dalam aliran air yang keluar dari water heater. Sinyal listrik yang terdeteksi oleh sensor dikarakterisasi untuk mendapatkan nilai arus dan tegangan pada berbagai nilai tegangan dan kondisi hambatan tubuh. Karakterisasi dilakukan terhadap variasi tegangan pada kondisi hambatan konstan dan variasi hambatan pada tegangan konstan. Variasi hambatan dilakukan mulai dari 1 sampai $100 \mathrm{~K} \Omega$ setiap $1 \mathrm{~K} \Omega$. Variasi hambatan ini untuk menggantikan nilai hambatan tubuh manusia mulai dari keadaan kulit basah sampai kering. Hambatan kulit tubuh manusia berkisar dari 300 sampai 1000 ohm [1]. Hasil karakterisasi diperoleh arus dan tegangan yang dapat digunakan untuk menentukan pengaruhnya terhadap kesehatan. Rancangan sensor seperti terlihat pada Gambar 1.

\section{HASIL DAN PEMBAHASAN}

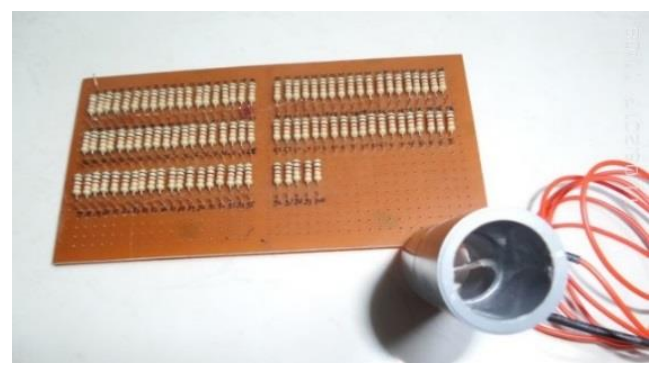

Gambar 2. Sensor kebocoran arus listrik dan hambatan uji
Sensor kebocoran arus dibuat dari bahan pipa PVC dan elektroda tembaga. Sambungan pipa PVC berukuran $1 / 2$ inch diberi lobang untuk memasukkan elektroda tembaga. Sambungan ini dapat langsung dipasang pada pipa aliran air yang keluar dari water heater. Elektroda yang terdapat di dalamnya yang bertugas mendeteksi apabila terjadi kebocoran arus listrik dalam aliran air. Sementara hambatan uji sebagai pengganti hambatan tubuh manusia menggunakan hambatan tetap sebesar $1 \mathrm{~K} \Omega$ sebanyak 100 buah. Rangkaian hambatan disusun dengan konfigurasi seri, sehingga hambatan totalnya sebesar $100 \mathrm{~K} \Omega$. Tampilan sensor dan variasi hambatan seperti terlihat pada Gambar 2.

Karakterisasi pertama dilakukan terhadap sensor adalah variasi tegangan kebocoran arus untuk hambatan konstan. Nilai hambatan ditetapkan sebesar $1 \mathrm{~K} \Omega$, $10 \mathrm{~K} \Omega, 20 \mathrm{~K} \Omega, 50 \mathrm{~K} \Omega$ dan $100 \mathrm{~K} \Omega$. Tegangan divariasikan mulai 0 sampai 220 volt AC setiap 5 volt. Hasil pengukuran arus pada variasi tegangan seperti pada grafik Gambar 3. Menurut [4], sensasi syok tidak nyeri terjadi pada sengatan arus listrik sebesar $5 \mathrm{~mA}$. Batasan efek sensasi syok tidak nyeri ditetapkan sebagai batas terendah. Hal ini dengan pertimbangan bahwa pada efek ini manusia masih dapat memberikan reaksi untuk menyelamatkan diri. Sementara efek yang lebih besar dari ini sudah mulai membahayakan bagi kondisi tubuh. Hasil analisis menunjukkan bahwa sensasi syok tidak nyeri terjadi pada tegangan AC yang berbeda untuk kondisi hambatan tubuh yang berbeda. Batas tegangan yang mulai memberikan sensasi syok tidak nyeri seperti terlihat pada Tabel 2. 
Tabel 2. Efek syok tidak nyeri dari kebocoran arus listrik dalam air untuk kondisi hambatan tubuh yang berbeda.

\begin{tabular}{lrrrrrr}
\hline & $\mathbf{1} \mathbf{K} \boldsymbol{\Omega}$ & $\mathbf{1 0} \mathbf{K} \boldsymbol{\Omega}$ & $\mathbf{2 0} \mathbf{K} \boldsymbol{\Omega}$ & $\mathbf{3 0} \mathbf{K} \boldsymbol{\Omega}$ & $\mathbf{5 0} \mathbf{K} \boldsymbol{\Omega}$ & $\mathbf{1 0 0} \mathbf{K} \boldsymbol{\Omega}$ \\
\hline Arus listrik (mA) & 5,16 & 5,08 & 4,95 & 4,9 & 4,34 & 2,35 \\
\hline Tegangan (VAC) & 30 & 75 & 120 & 165 & 220 & 220 \\
\hline
\end{tabular}

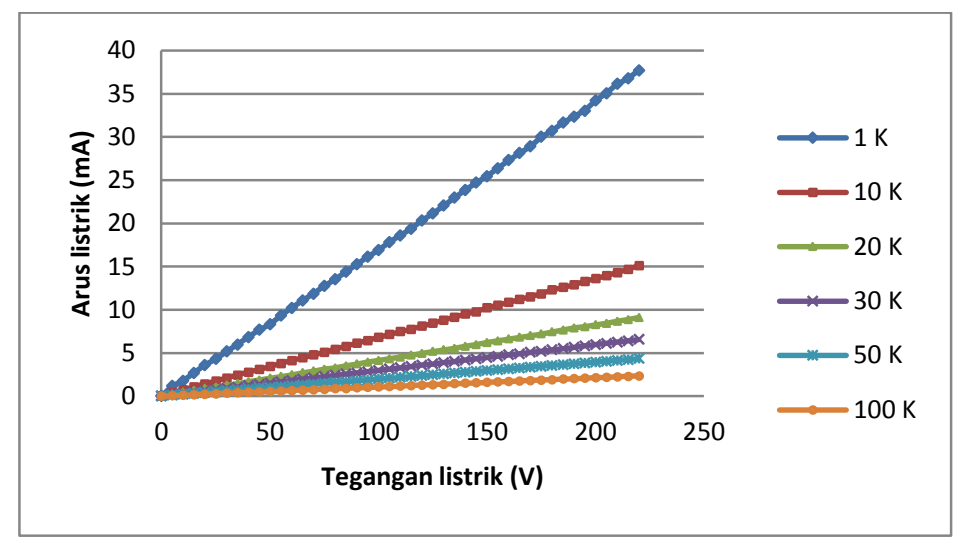

Gambar 3. Respon kebocoran arus listrik dalam air pada variasi tegangan

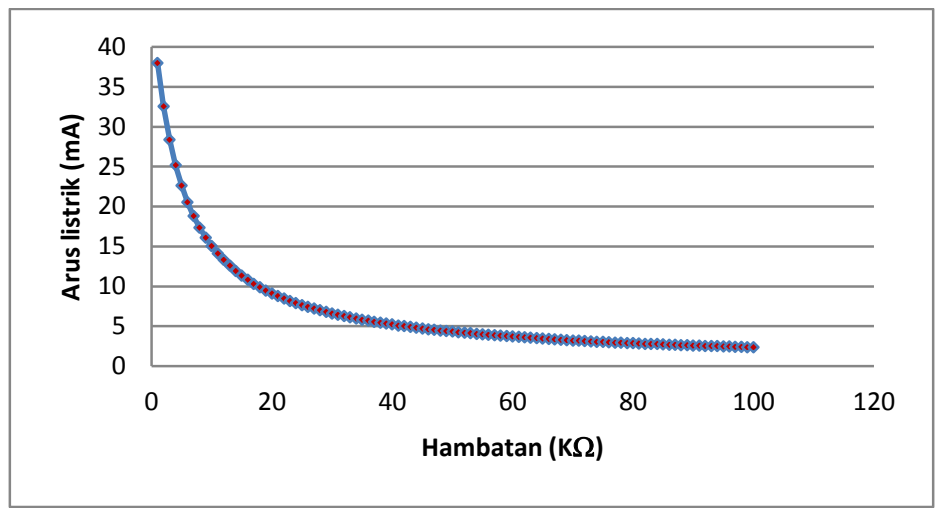

Gambar 4. Respon kebocoran arus listrik dalam air pada variasi hambatan untuk tegangan tetap $220 \mathrm{~V}$.

Karakterisasi yang kedua dilakukan terhadap variasi hambatan tubuh pada kondisi tegangan tetap. Tegangan ditetapkan sebesar $220 \mathrm{~V}_{\mathrm{AC}}$, sementara hambatan pengganti tubuh divariasi dari 1 sampai $100 \mathrm{~K} \Omega$ setiap $1 \mathrm{~K} \Omega$. Hasil pengukuran dapat ditunjukkan seperti pada Gambar 4. Berdasarkan pada data hasil pengukuran untuk tegangan tetap sebesar $220 \mathrm{~V}_{\mathrm{AC}}$, sensasi syok tidak nyeri mulai dirasakan pada hambatan tubuh $42 \mathrm{~K} \Omega$ dengan arus kebocoran sebesar 4,99 mA. Dengan demikian, untuk hambatan tubuh yang lebih rendah dari $42 \mathrm{~K} \Omega$ akan merasakan efek kejutan listrik yang lebih besar.

Berdasarkan pada hasil karakterisasi sensor dapat dinyatakan bahwa sensor dapat merespon terjadinya kebocoran arus listrik AC dengan baik. Dengan demikian sensor dapat diaplikasikan pada jaringan pipa pemanas air. Sensor dapat diintegrasikan dengan rangkaian pengendali sebagai sistem otomatisasi. Dengan sistem otomatisasi semacam ini diharapkan akan dapat menekan jatuhnya korban jiwa yang diakibatkan oleh kebocoran arus listrik dalam air. 


\section{KESIMPULAN}

1. Sensor dapat merespon kebocoran arus listrik dalam air dari tegangan 5 hingga $220 \mathrm{~V}_{\mathrm{AC}}$.

2. Sensasi syok tidak nyeri mulai dirasakan pada kondisi hambatan tubuh $1 \mathrm{~K} \Omega$ terjadi pada tegangan $30 \mathrm{~V}$, hambatan $10 \mathrm{~K} \Omega$ pada tegangan $75 \mathrm{~V}$, hambatan $20 \mathrm{~K} \Omega$ pada tegangan $120 \mathrm{~V}$, hambatan tubuh $30 \mathrm{~K} \Omega$ pada tegangan 165 V. Sementara pada hambatan 50 $\mathrm{K} \Omega$ dan $100 \mathrm{~K} \Omega$ tidak terjadi sensasi syok tidak nyeri sampai pada tegangan $220 \mathrm{~V}$.

3. Kebocoran pada tegangan $220 \mathrm{~V}_{\mathrm{AC}}$ mulai memberikan efek sensasi syok tidak nyeri pada kondisi hambatan tubuh $\leq 42 \mathrm{~K} \Omega$.

\section{DAFTAR PUSTAKA}

[1] G. N. Reddy, "Effects of Wireless Electricity on Human Bodies," Int. J. Eng. Trends Technol., pp. 2567-
2569, 2013.

[2] A

A. Circuits, www.allaboutcircuits.com," 2015.

[3] A. E. Cekin, "Childhood Deaths Due To Electrocution In Adana," J. Exp. Med., pp. 73-80, 2005.

[4] H. C. S. D. Prasad, A.K. Sharma, "Electric Shock and Human Body," in Electric Shock and Human Body, India: National Institite of Technology, 2010.

[5] J. Hanning, R.C. Lee, and D. Zhang, "Biophysical Injury Mechanisme In Electrical Shock Trauma," Аnnu. Rev. Biomed. Eng., pp. 477-509, 2000 .

[6] M. Alonso, F. Finn, and J. Edward, Dasar-Dasar Fisika Universitas. Jakarta: Erlangga, 1994. 
Hartono dkk.: Sensor Kebocoran Arus Listrik 